\title{
El storytelling corporativo como instrumento para el crecimiento de la reputación. El caso de Grupo Bimbo
}

\author{
Claudia Ivett Romero Delgado ${ }^{*}$, Juan Carlos Carrillo Cal y Mayor ${ }^{2}$
}

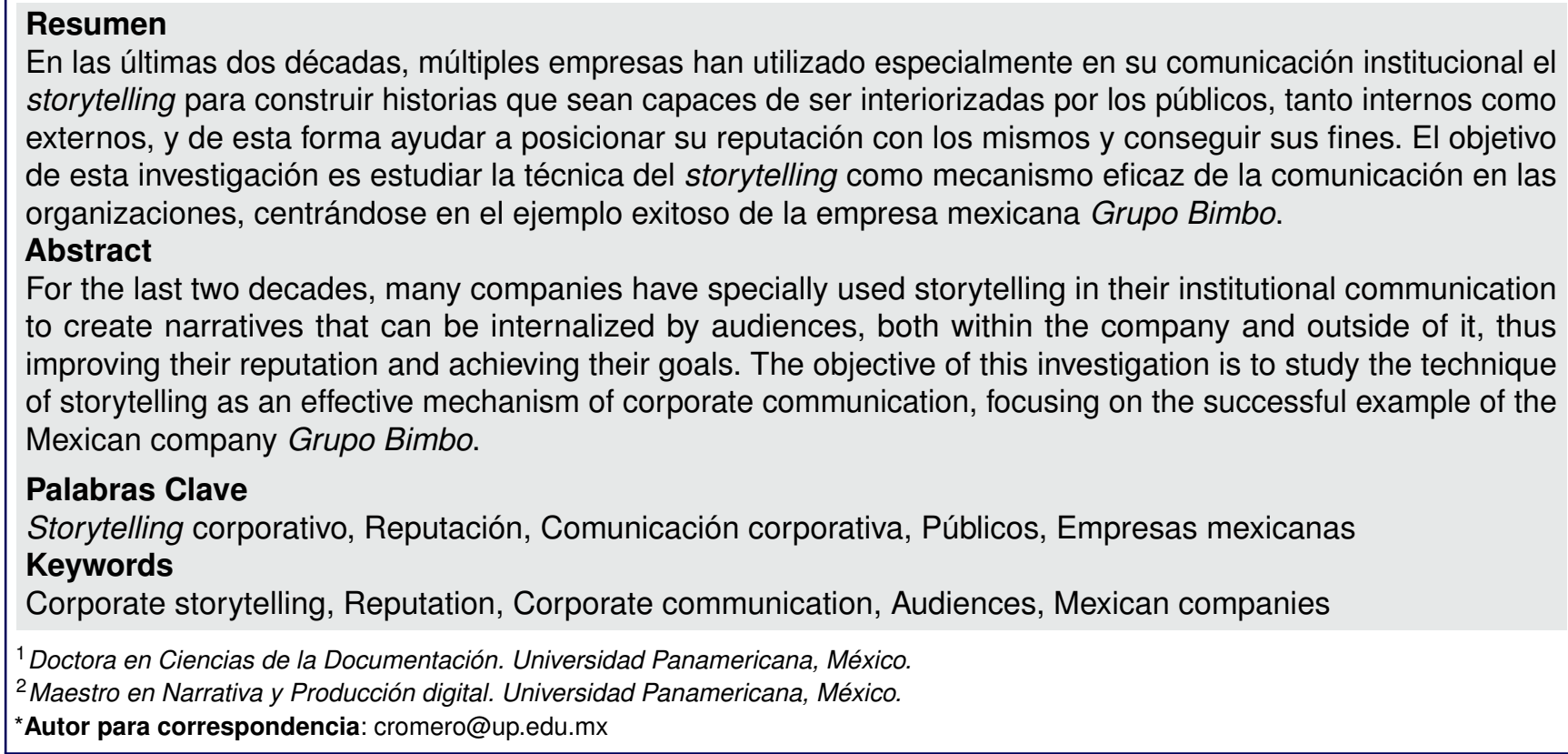

En las últimas dos décadas, múltiples empresas han utilizado especialmente en su comunicación institucional el storytelling para construir historias que sean capaces de ser interiorizadas por los públicos, tanto internos como externos, y de esta forma ayudar a posicionar su reputación con los mismos y conseguir sus fines. El objetivo de esta investigación es estudiar la técnica del storytelling como mecanismo eficaz de la comunicación en las organizaciones, centrándose en el ejemplo exitoso de la empresa mexicana Grupo Bimbo.

\section{Abstract}

For the last two decades, many companies have specially used storytelling in their institutional communication to create narratives that can be internalized by audiences, both within the company and outside of it, thus improving their reputation and achieving their goals. The objective of this investigation is to study the technique of storytelling as an effective mechanism of corporate communication, focusing on the successful example of the Mexican company Grupo Bimbo.

Palabras Clave

Storytelling corporativo, Reputación, Comunicación corporativa, Públicos, Empresas mexicanas

Keywords

Corporate storytelling, Reputation, Corporate communication, Audiences, Mexican companies

${ }^{1}$ Doctora en Ciencias de la Documentación. Universidad Panamericana, México.

${ }^{2}$ Maestro en Narrativa y Producción digital. Universidad Panamericana, México.

*Autor para correspondencia: cromero@up.edu.mx

\section{Introducción}

La comunicación corporativa utiliza distintas técnicas para conseguir los objetivos que mejoren su reputación, no solo con sus públicos internos, sino también con los externos. Se trata de técnicas que varían según la disciplina comunicativa que utilice la organización para coordinar su comunicación en un ambiente cambiante (Hallahan et al. 2007). Una de esas técnicas aplicada a la comunicación de las organizaciones, es denominada por algunos autores como corporate storytelling u organizational storytelling (Gill, 2011b; Denning, 2006), storytelling corporativo (Costa-Sánchez, 2014) o storytelling empresarial (Arab et al., 2011).
La eficacia de esta técnica para conseguir los fines de la comunicación corporativa radica en el hecho de que el ser humano por naturaleza siempre ha contado historia, es un ser que narra u homo narrans, en términos de John Niles (2010). Jean Paul Sartre, afirmaba que el hombre vive rodeado de sus historias y de las ajenas, ve a través de ellas todo lo que le sucede y trata de vivir su vida como si la contara (Sartre, 1938:32). Por su parte, Robert McKee afirma que las historias narradas son poderosas porque no apelan únicamente a la racionalidad de la persona, sino también a sus emociones (McKee, 2003), lo que les da una capacidad de mover a la acción con mayor facilidad. Igualmente las narraciones son útiles para entender de modo más sencillo algunas ideas, a diferencia de los conceptos abstractos. No 
por nada históricamente ideas complejas se han transmitido muchas veces en forma de parábolas o de fábulas.

El storytelling, según Christian Salmon, se define como un arma de distracción masiva, que no admite el estatus de ficción; se trata de una manera distinta de gestionar los relatos para utilizar la narración como una manera de convencer y movilizar la opinión (Salmon, 2008:9). Aunque el autor toma el storytelling de forma un tanto negativa, esta estrategia persuasiva se vuelve inspiradora cuando es utilizada por un líder honesto y responsable (Sadows \& Roche, 2013:17).

Así, mientras que algunos métodos comunicativos pueden resultar arduos o intrusivos para el receptor, las historias siempre son más amables. La anécdota es habitualmente más incisiva y atractiva que el concepto puro, aunque tiene que basarse en él y dirigirse a él, especialmente cuando se tiene un fin comunicativo determinado.

Pero, ¿realmente el storytelling ayuda a las empresas mexicanas a mejorar su reputación corporativa? Algunos autores han detectado acciones que ayudan a mejorar esta reputación, tales como la humildad en las relaciones con todos los públicos, saber escuchar, ser transparente, colaborar, comunicar, compartir y que los directivos figuren más como administradores de las empresas y no como dueños sin fronteras de estas (López, 2014:4).

Según el Reputation Institute, para contar con una buena reputación una empresa necesita admiración, confianza, buena impresión y estima; estos atributos deben ser encontrados por los consumidores y una forma para que esto resulte es el storytelling, pues se puede leer el éxito de una empresa a través de una historia que sea el eje narrador a lo largo de sus años de existencia.

Este artículo abordará primero el estado de la cuestión en torno al storytelling en la comunicación de las empresas, para después ubicar esta técnica comunicacional en el ámbito de las empresas mexicanas y finalmente demostrar su eficacia con el ejemplo de la narración de historias en la comunicación de la empresa mexicana Grupo Bimbo.

\section{Rasgos del storytelling en la comunicación de las organizaciones}

Como sucede con la comunicación en general, el storytelling es más intuitivo que planeado. Resulta una actividad más bien informal, en cuanto que brota naturalmente de la persona, independientemente de su contexto o preparación. Aunque puede diseñarse una estrategia de storytelling, la experiencia inmediata indica que cualquiera puede contar una historia, aunque el contar bien una buena historia, sí requiera cierta habilidad o capacitación (McKee, 2003; Dowling, 2006; Gill, 2011b).

En el ámbito de la comunicación organizacional resulta especialmente interesante el uso del storytelling, pues las historias compartidas en el entorno de una organización -desde algún rumor que pueda correr entre los empleados de una empresa, hasta la historia de una organización determinada diseminada en anécdotas, libros o películas- crean un sentido de pertenencia y configuran la percepción que se tiene de la organización desde dentro como desde fuera de ella: "through the telling and retelling of stories, organisational life is created" (Sinclair, 2005: 57).

Autores como Robert McKee han abordado la importancia del storytelling en la comunicación organizacional. McKee (2003) aplica su experiencia en personajes, trama, conflicto y deseo a las ventajas que puede tener esa estructura comunicacional en un ambiente corporativo. Tanto él como otros autores subrayan su eficacia especialmente como un modo de persuasión. "Stories serve a persuasive communication function for organizations by representing personal, interpersonal, and corporate perspectives" (Barker \& Gower, 2010: 304).

Así, aunque en su amplitud el hecho de narrar historias puede tener innumerables efectos comunicativos, dentro de los fines que puede tener la comunicación organizacional, el storytelling es una herramienta usada más para la persuasión (McKee, 2003), para tener una comunicación interna efectiva (Gill, 2011a) y para construir la imagen y reputación de la organización (Dowling, 2006). También ha sido recomendada para una eficaz gestión del cambio (Gill, 2011b).

Por su parte, Denning (2006) recoge ocho diferentes patrones narrativos, dependiendo de qué objetivo se busque: ya sea mover a la acción (las llamadas "historias trampolín" o springboard stories); comunicar quién eres; transmitir valores; comunicar quién es la empresa (branding); fomentar la colaboración; desmentir un rumor; compartir conocimiento; o guiar a los stakeholders hacia el futuro. 
Así, una organización puede fomentar algunas narraciones determinadas o difundirlas expresamente en productos comunicativos concretos, pero debe ser consciente de que muchas otras narraciones surgirán espontáneamente dentro de la organización y en su entorno, como suceden en cualquier organización por el hecho de estar formadas por personas (Boje, 1991); y de que esas narraciones no siempre irán alineadas con sus objetivos y que incluso pudieran serle perjudiciales.

\section{La contribución del storytelling corporativo al aumento de reputación}

Las empresas son organizaciones narrativas, atravesadas por múltiples relatos, que constituyen el terreno de un diálogo constante entre relatos que se oponen o se complementan (Boje, 2000). Ahora se construye una imagen para crear un halo alrededor de los productos o servicios de una empresa: de esta forma, cuando las marcas hablan, los públicos escuchan atentamente; cuando las marcas actúan, los consumidores los siguen: se convierten en personajes en la vida del consumidor.

Dentro de la ya mencionada informalidad o naturalidad del storytelling en una organización, su eficacia como método de comunicación institucional también ha quedado patente en modelos más estructurados como el Storytelling Model of Organisational Communication de Barker y Gower (2010:302), que al reconocer a todo ser humano como un potencial narrador (storyteller) con la habilidad de enviar y recibir mensajes, afirma que el storytelling establece una realidad cargada de valor, construye un terreno común entre todos los participantes y proporciona un método más rápido de establecer relaciones sociales.

Este modelo aplica la estrategia del storytelling -del que dice que en sí mismo está cargado de significado, es innato a la personas, orientado a la acción y transcultural- al conjunto de públicos tanto internos como externos, lo que Barker y Gower (2010) denominan organizational diversity continuum, con lo que aseguran que se mejora la comunicación, se fortalecen las relaciones y aumenta la productividad en todo el organismo.

A modo de revisión del estado de la cuestión, al construir un marco teórico para hablar sobre el uso del storytelling para mantener la lealtad de los empleados mientras hay cambios en una organización, Robert Gill (2011b) elaboró tres tablas a partir de los estudios de varios autores: una sobre los beneficios del storytelling corporativo; otra sobre las claves para componer, desarrollar e implementar una buena narración corporativa; y una tercera sobre las limitaciones que tiene el uso del storytelling en este ámbito de la comunicación.

En cuanto a los beneficios, Gill (2011b) señala que el storytelling es un medio efectivo de comunicación con los públicos internos, pues es más comprometedor (engaging) y atractivo (appealing) para ellos. Aclara que los objetivos de la historia pueden seguir siendo los mismos incluso cuando el contenido es adaptado por el narrador para hacer historias más personales, algo recomendable pues el conocimiento presentado a través de la narración es más creíble a medida que los receptores aplican su propia interpretación y experiencias a la información.

También enumera entre los beneficios el que las historias corporativas eficaces apelan a las emociones y tienen un ciclo de vida relacionado con la organización. Igualmente, los empleados pueden adoptar una noción de identificación con las narraciones e historias corporativas aplicando sus propias experiencias al mensaje; y cuando los empleados se sienten cómodos con los valores y las prácticas de trabajo de su organización, se convierten en activos importantes para mejorar la reputación de la empresa (Gill, 2011b).

Ahora bien, no cualquier historia tendrá un efecto positivo en la comunicación de una institución, o le ayudará a alcanzar sus fines. E incluso las historias que sí estén diseñadas para tenerlo deben tomar en cuenta algunos elementos negativos dentro de la misma. En esta línea, McKee (2003) insiste en el realismo que aporta a la narración el que tenga como elemento principal un conflicto, lo que necesariamente implicará que no sea una historia positiva en todos sus matices, sino que tenga elementos negativos.

Entre las claves para componer, desarrollar e implementar una buena narración corporativa, Gill (2011b) -de nuevo incorporando opiniones de varios autores- señala que esta debe ser tal que aumente el conocimiento de los empleados sobre la organización y su misión, sus estrategias y valores, permitiendo que le den sentido a la narración. Una historia bien diseñada para una buena comunicación debería brindar importancia a los empleados, sus roles y sus preocupaciones, valiéndose de la memoria colectiva y los personajes reales que pueda incluir. 
De la misma manera, una "buena" historia en cuanto a los fines organizacionales, deberá mostrar una lucha entre la expectativa y la realidad al incluir tanto aspectos positivos como negativos, fortalezas y debilidades, así como no presentar el conflicto como algo ya resuelto, sino extender el valor más allá del momento inmediato haciendo que los empleados formen parte de la solución. Naturalmente, los valores de la narración en cuestión deberán permanecer fieles a la marca y los valores de la organización (Gill, 2011b).

La nueva organización comunica tanto para adentro como para afuera, gracias a estrategias alternas a la narración y contranarración; de este modo las empresas no se vuelven justas, solo cambian de relato. Se emprenden ambiciosas historias narrativas de cambio para sus públicos internos y externos, y de esta forma las hace parte de ella y cambia lo malo por lo bueno desde dentro hacia fuera.

La comunicación de la empresa busca comprometerse en una relación duradera y emocional con el público, de tal forma que la experiencia se torna importante y se crea una relación, singular y emocional, entre la empresa y sus públicos; pero es importante aclarar que no solo se trata de una mera visibilidad (Salmon, 2008:124), sino de un compromiso que inicia desde la empresa. Las empresas aspiran a encontrar una identidad fuerte y coherente, que hable tanto a los públicos internos como a los externos, y que pueda condensar en un relato coherente todos sus elementos constitutivos. En ese sentido, una empresa es también un grupo social, conformado por sus empleados.

Un grupo social es un conjunto de personas que persiguen un fin común, para lo cual establecen una red de relaciones producto de la interacción y la comunicación, cuya conducta se rige por un conjunto de normas culturales, y que comparten intereses, creencias y valores comunes. Estas normas, intereses, creencias y valores establecen la identidad y los límites del grupo y lo diferencian de su entorno (Rodríguez, 2015:11).

A través del storytelling es mucho más sencillo que los públicos internos y externos se apropien de historias con las que se identifican, y les den un sentido de pertenencia que permita ganar y mantener la confianza. Por eso se convierte en la herramienta de gestión para fortalecer la lealtad y el sentido de pertenencia.

La reputación a través del storytelling corporativo se convierte en un argumento clave para la búsqueda de una diferenciación sostenible, de la creación de valor a largo plazo, que implica asumir el rol de la empresa al servicio de sus grupos de interés, donde solo la creación de valor compartido y equilibrado permitirá un crecimiento sostenible y capaz de generar cohesión social (Carreras, Alloza y Carreras, 2013:31).

Así se fundamenta la eficacia del storytelling corporativo para aumentar la reputación e influir en la percepción que los públicos tienen sobre cualquier organización, con la ventaja de que a través de contar historias los impactos son más vivenciales.

\section{Las empresas mexicanas y sus peculiaridades}

Se ha dicho que las empresas en México son conservadoras y orgullosas y que una de sus principales fallas es que no saben cuáles serán sus necesidades en el futuro (Murillo, 2015). Los cambios tecnológicos e industriales son una constante a nivel global y la competencia cada vez es más feroz. Según datos del Instituto Nacional de Estadística y Geografía (INEGI) existen 4.2 millones de unidades económicas en México, de las cuales, el $99.8 \%$ son consideradas Pequeñas y Medianas Empresas (Pymes), que aportan $42 \%$ del Producto Interno Bruto (PIB) y generan el $78 \%$ del empleo.

Existen empresas mexicanas que han sobrepasado fronteras y que, según la Bolsa Mexicana de Valores (BMV), en 2017 cinco de ellas (América Móvil, Walmex, Femsa, Alfa y Grupo Bimbo) concentraban ingresos equivalentes al $58 \%$ del Producto Interno Bruto (PIB), lo que las convierte, deseablemente, en organizaciones dispuestas a abrirse a los cambios para poder conquistar mercados internacionales a gran escala. Estas organizaciones no solo innovan en tecnología, sino que lo más importante es que se comprometen con sus empleados y consumidores, y es aquí donde el storytelling funciona, pues se convierte en una pieza clave para conectar con sus diferentes stakeholders. 
Si las empresas tienen una estrategia clara de crecimiento, es muy probable que el mercado pueda crecer exponencialmente, pero la capacidad para dar servicio no pueda hacerlo. Es aquí donde también es importante contar historias hacia dentro y fuera, debido a que las historias pueden tener efectos reales en cambios favorables de actitud en los empleados y con ello un mejor desempeño y una mayor productividad.

Por otro lado, en México existen al menos diez casos de empresas nacionales que son familiares y su crecimiento e internacionalización se han dado con mucho éxito, como son Grupo Bimbo, La Costeña, Sigma, Gruma, Grupo Lala, Bachoco, Alsea, Grupo Herdez, Bafar y Kuo (Jiménez, 2018). En este tipo de organizaciones se presentan relaciones duales familiar/personal y empresarial/laboral con los miembros de la familia, lo que condiciona que las empresas tengan éxito (Gómez, 2016:41). A este éxito contribuye el que muchos de sus empleados no estén allí únicamente por el sueldo, sino también por los beneficios laborales con los que cuentan y la vinculación que sienten con la empresa.

Estas grandes empresas han implementado el storytelling como elemento fundamental dentro de la arquitectura de marca y crean historias que conectan con los valores de la empresa y con sus intereses, además de las creencias e ideales de sus públicos.

\section{La familia más dulce de México}

Juan Servitje Torrallardona llegó desde España en 1904 a México, donde comenzó a trabajar en una empresa de unos conocidos llamada La Flor de México. Era una pastelería que se hizo de buena fama por la calidad de su repostería en la capital del país. En 1915, Josefina Sendra llegó también de España para trabajar en La Flor de México, donde conoció a Juan Servitje y contrajeron nupcias. El 20 de noviembre de 1918 nació Lorenzo Juan José Servitje Sendra, el primero de cinco hijos de Juan y Josefina (Frausto, 2016:315).

En la década de los 20, con la creación de Pan Ideal, se incrementó la comercialización del pan de caja, pero había serios problemas de distribución y muchos de sus clientes se quejaban por las malas condiciones en que se vendían (Frausto, 2016:316).
En 1926, Juan Servitje comenzó a trabajar en la Pastelería Ideal y un par de años más tarde fundó la pastelería El Molino con algunos socios. La empresa de los Servitje comenzó a ganar clientela, y compraron maquinaria para hacer bolillos, pero tuvieron problemas porque sus empleados no querían utilizarla, pues creían que se quedarían sin trabajo (Servitje, 2009:4).

En 1936, cuando Lorenzo cumplió 18 años y se encontraba cursando el primer año de la licenciatura en contaduría, su padre murió y él tuvo que dejar la escuela para convertirse en el gerente de la pastelería El Molino (Servitje, 2009:4). Su tío, Jaime Sendra, que era el jefe de producción de El Molino, le propuso instalar una fábrica de pan de caja. En 1944 comenzó a tomar forma el negocio y en ese mismo año Lorenzo se casó con Carmen, hija de Daniel Montull, dueño de las fábricas de cerillos La Imperial y La Central (Servitje, 2003:9).

El suegro de Lorenzo les ofreció un terreno en la colonia Santa María Insurgentes, que pagaron poco a poco y el 2 de diciembre de 1945 nació Panificadora Bimbo, con 34 trabajadores, diez camiones y cuatro productos: Pan Grande, Pan Chico, Pan Negro y Pan Tostado. El osito, emblema de la compañía, aparecía impreso ya en las envolturas de celofán de esos primeros productos (Frausto, 2016:314).

A mediados de 2018, Grupo Bimbo contaba con 196 plantas, más de 138 mil colaboradores, más de tres millones de puntos de venta, y alcanzó ventas anuales por 13,890 millones de dólares. Bimbo produce y distribuye pan de caja fresco y congelado, bollos, galletas, pastelitos, english muffins, bagels, productos empacados, tortillas, botanas saladas, confitería, entre otros. Tiene presencia en 32 países de América, Europa, África y Asia, y cuenta con una de las redes de distribución más grandes del mundo (Grupo Bimbo, 2018).

\section{La reputación de Bimbo a través de contar historias}

Según el Monitor Empresarial de Reputación Corporativa MERCO México 2017, Grupo Bimbo se encuentra en el primer lugar en reputación de una lista de 100 empresas en México. Es considerada como una empresa mexicana fuerte, lo que indica que goza de un importante nivel de confianza, admiración y estima entre el público nacional. No solo es la percepción de sus consumidores, también es la opinión de sus 


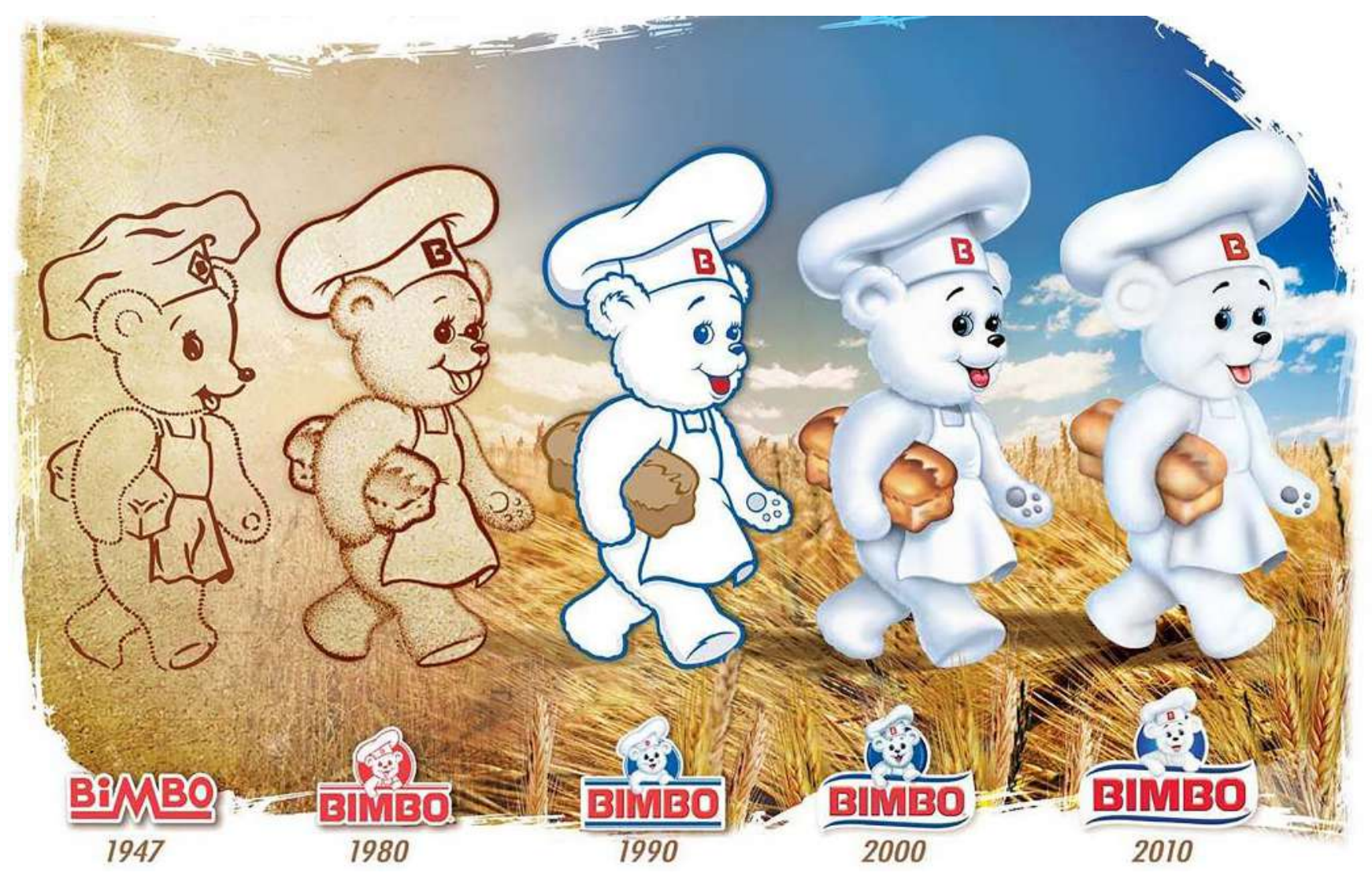

Figura 1. El osito Bimbo en el tiempo. Fuente: Villeda (2018).

empleados, proveedores y demás stakeholders (Hernández, 2017) que emiten opiniones favorables.

Una de las grandes fortalezas que tiene Bimbo para contar historias y que sus públicos, tanto internos como externos, las hagan suyas, es el personaje del osito, al que las familias mexicanas consideran un elemento de su intimidad cotidiana, por haberlo percibido en su entorno familiar -y en un ámbito tan propio del hogar como es la cocina- desde su primera infancia. El osito Bimbo es la pieza clave de la narrativa de la comunicación de esta empresa.

A través del osito -cuyo color blanco remite a la idea de limpieza y candor- sus colaboradores saben, por ejemplo, que la pulcritud de su vestimenta es muy importante y que siempre deben mantener su ropa limpia e impecable pues es la clave para la buena reputación de la marca. Bimbo utiliza el storytelling para que los stakeholders a través de una implicación subjetiva, se identifique con unos contenidos que hacen suyos por propio convencimiento (Martín, 2009). La imagen que refleja el osito como personaje es tan relevante, convincente, entendible y auténtica que genera un cambio de comportamiento en sus públicos que abre la posibilidad de educar de una manera muy sencilla.

Otro aspecto narrativo destacable es la historia de vida de Lorenzo Servitje Sendra, que ayuda a que el consumidor se identifique con un hombre mexicano luchador, que nunca se dio por vencido, que trabajó en todos los puestos de su gran imperio y que aun con escenarios de crisis económica sacó adelante a la empresa de alimentos más grande de México, además del papel filantrópico que desempeñó en la sociedad mexicana. Aquí trabajan muy bien la conexión de la marca con el usuario.

Los mensajes en sus plataformas de redes sociales, así como su video corporativo, destacan la figura de Lorenzo Servitje -a cuyo nombre anteponen un respetuoso "Don"- con la connotación de tradición y de empresa familiar que eso implica. Es necesario destacar la importancia del liderazgo de las cabezas que hacen que las historias se conviertan en parte de la historia de sus colaboradores, transmitiendo su identidad, 
valores, sentido de pertenencia, etcétera (Sadows \& Roche, 2013:16).

Las historias que cuenta Bimbo en sus plataformas de redes sociales apelan igualmente a la emotividad y al niño que aún conservamos dentro, sin olvidar que sus colaboradores son siempre su prioridad y lo más importante para trabajar éticamente. La narración de historias en el entorno laboral no solo permite crear un vínculo dentro de los equipos de trabajo, sino que también lo crea entre los equipos (Sadows \& Roche, 2013:25). De esta forma, se vuelve una prioridad nutrir el contenido audiovisual en las redes sociales, pues los mismos usuarios lo generan, evalúan y distribuyen (Freire, 2017:41).

La empresa realiza esfuerzos para mejorar la calidad de vida personal y profesional de sus colaboradores, pues no solo les imparte cursos, sino que contribuyen con revisiones de salud, mejora de carrera profesional y diversos programas que incluyen a las familias de los colaboradores para que sean parte de la empresa. Se vuelve primordial reflejar estas prácticas en relatos creíbles, eficaces y capaces de generar vínculos emocionales y relacionales con las personas (Freire, 2017:25). Así se exige la necesidad de introducir a los stakeholders como protagonistas de las historias que se cuentan, pero al mismo tiempo, desarrolla una capacidad para juzgarlas, distribuirlas, y si las considera atractivas, alargarlas, incluso si su universo narrativo encuentra una comunidad interesada y motivada a hacerlo.

Estas narrativas que se cuentan en Grupo Bimbo se vuelven cotidianas debido a que las personas son creadoras y demandantes de historias, relatos complejos y únicos que se consumen como contenido audiovisual en cápsulas de ocio. Esta información se distribuye a través de sus plataformas de redes sociales, donde se cuentan historias de sus empleados, de sus plantas y de sus productos que apelan a que el público tanto interno como externo las hagan suyas y las valoren como parte de su vida en familia.

Futbolito Bimbo es otro ejemplo positivo de storytelling corporativo de la marca, pues cuenta historias de niños mexicanos que se apasionan por el deporte (fútbol soccer), que comen sanamente y para quienes la escuela y la familia forman un papel muy importante en su desempeño y crecimiento. De este modo las historias no solo son contadas por la empresa, sino por quienes forman parte de los públicos internos $\mathrm{y}$ externos. Por tanto, se eleva su reputación de ser una empresa comprometida con México y, al centrarse en el ejercicio físico, se sale al paso de una crítica actual a las empresas que producen alimentos altos en calorías, de no favorecer a la salud, especialmente de los niños.

Para poder integrar a la familia de los trabajadores, la empresa organiza carreras a partir de las cuales se integra material con el que posteriormente se contarán historias de vida -cómo se prepararon, cuántas horas invirtieron en la preparación- y se transmite que correr no solo unió a la familia, sino que bajaron de peso y ahora mantienen vidas más saludables.

La empresa también contribuye a la unión de la familia plantando árboles y ayudando a que crezcan y se conviertan en pulmones de las poblaciones a las que pertenecen. De esta forma genera lazos estratégicos con los colaboradores y hace que se sientan identificados con la organización y al mismo tiempo se conviertan en embajadores de marca hacia el exterior.

Grupo Bimbo ha establecido y elevado su reputación a través de una narrativa específica que ha hecho que sea percibida, tanto por su público interno como externo, como una empresa comprometida con sus colaboradores y con el medio ambiente, ética, que trata de retornar parte de lo que la sociedad le ha dado y que es familiar por su origen y presencia entre las familias mexicanas, así como por el modo de abordar y comunicar su relación con sus empleados y consumidores.

\section{Conclusiones}

La relevancia y eficacia del storytelling dentro de la comunicación organizacional son hoy ampliamente reconocidas. Las historias juegan un papel esencial en la comunicación de una organización, pues resultan propicias para mover a la acción a las partes involucradas y para generar identificación y benevolencia hacia la institución. Por sus características, y al ser algo natural en el ser humano, las narraciones apelan no solo a la razón sino a las emociones, generando una identificación y una motivación más enraizadas en la persona.

Especialmente eficaz se ha revelado el uso del storytelling en la persuasión, la aceptación del cambio al interior de una organización, la generación de reputación e imagen de las instituciones y, en general, para inspirar a los distintos 
públicos a través de historias bien construidas y no solamente insertar un mensaje determinado.

Al hacer énfasis en los beneficios del storytelling corporativo, las empresas deben también enfatizar en el impacto, la inmersión, la integración y la interactividad con sus audiencias, para que las narraciones -como pueden ser los trascendidos entre empleados, rumores, falsedades e incluso difamaciones o calumnias desde fuera de la institución- no provoquen crisis de comunicación.

Uno de los factores que ayudan a que el storytelling corporativo funcione para incrementar la reputación son los empleados, puesto que son un factor de importancia decisiva en la actualidad. Si no sienten que su labor es reconocida, se irán a otra empresa donde puedan ser más valorados, pero cuando son motivados a través de historias son los primeros en elevar la reputación de la empresa, como queda patente en el caso de Grupo Bimbo.

La imagen y la reputación se vuelven partes esenciales del capital estratégico de una organización, y este a su vez se convierte en una fuente de generación de confianza, que es un factor imprescindible a la hora de mantener relaciones tanto con los públicos internos como con los externos.

Las empresas mexicanas como Grupo Bimbo -que a través de su narrativa se ha convertido en un elemento esencial de la vida familiar en México- han utilizado el storytelling corporativo para mantenerse dentro de las empresas con la mejor reputación corporativa.

\section{Referencias}

Arab, A. B., y Domingos, A. A., \& Dias, D. A. (2011). Storytelling Empresarial: relações públicas contador de histórias. Intercom-Sociedade Brasileira de Estudos Interdisciplinares da Comunicação.

Barker, R. T., \& Gower, K. (2010). Strategic Application of Storytelling in Organizations. Journal of Business Communication, 47(3), 295-312.

Boje, D. (1991). The Storytelling Organization: A Study of Story Performance in an Office-Supply Firm. Administrative Science Quarterly, 36(1), 106-126. doi:10.2307/2393432

Boje, D. (2000). Time and Nike. Symposium, Academy of Management, Toronto. Recuperado el 23 de abril de 2018 en https://business.nmsu.edu/ dboje/conferences /Acad2000NikeandTime.html\#Boje
Carreras, E., Alloza, A., y Carreras, A. (2013). Reputación corporativa. España: LID.

Costa-Sánchez, C. (2014). Storytelling e audiovisualização da comunicação corporativa: as chaves da campanha "Gracias por elegirnos" (Balay). Revista Organicom, 11(20), 162-176.

Denning, S. (2006). Effective storytelling: strategic business narrative techniques. Strategy \& Leadership, 34 (1), 42-48. doi: 10.1108/10878570610637885

Dowling, G.R. (2006). Communicating corporate reputation through stories. California Management Review, 49 (1), 82- 100 .

Frausto, S. (2016). Lorenzo Servitje. Una apuesta por el pan. Los amos de México. México: Temas de Hoy.

Freire, S. A. (2017). ¿ cómo crear un storytelling de marca?: de la teoría a la práctica profesional. España: Editorial UOC.

Gill, R. (2011a). Corporate storytelling as an effective internal public relations strategy. International Business and Management, 3(1), 17-25.

Gill, R. (2011b). Using storytelling to maintain employee loyalty during change. International Journal of Business and Social Science, 2(15), 23-32.

Gómez, E. (2016). De empresa familiar a familia empresarial. Reflexiones. México: Impre-Jal.

Grupo Bimbo. (2018). Página principal de Grupo Bimbo. Recuperado el 2 de mayo de 2018 en https://www.grup obimbo.com/es

Grupo BMV. (2018). Página principal de Grupo Bolsa Mexicana de Valores. Recuperado el 2 de agosto de 2018 en https://www.bmv.com.mx/

Hallahan, K., Holtzhausen, D., Van Ruler, B., Verčič, D., \& Sriramesh, K. (2007). Defining strategic communication. International journal of strategic communication, 1(1), 3-35.

Hernández, V. (2017). Factor Humano, clave para Bimbo. El Siglo de Torreón. Recuperado el 1 de mayo de 2018 en https://www.elsiglodetorreon.com.mx/noticia/1369 846.factor-humano-clave-para-bimbo.html

INADEM. (2018). Página principal del Instituto Nacional del Emprendedor. Recuperado el 2 de agosto de 2018 en https://www.inadem.gob.mx/

INEGI. (2018). Página principal del Instituto Nacional de Estadística y Geografía. Recuperado el 2 de agosto de 2018 en http://www.inegi.org.mx/

Jiménez, M. (2018). Las 10 empresas mexicanas que devoran al mundo. Forbes México. Recuperado el 2 de agosto de 2018 en https://www.forbes.com.mx/las-10-empresasmexicanas-devoran-al-mundo/

López, I. (2014). Observatorio global de intangibles en la comunicación empresarial y la gestión de los intangibles en España y Latinoamérica. Informe anual 2014. España: Gedisa. 
Martín, J.A. (2009). La eficacia del Storytelling. $M K$ Marketing+Ventas, $\mathrm{N}^{\mathrm{o}} 251$, pág. 08

McKee, R. (2003). Storytelling that moves people. Harvard Business Review, June 2003, 5-8.

Monitor Empresarial de Reputación Corporativa Merco México. (2018). Ranking Merco Empresas México 2017. Recuperado el 28 de abril de 2018 en http://merco.info $/ \mathrm{mx} /$ ranking-merco-empresas? edicion $=2017$

Murillo, C. (2015). Las empresas mexicanas son conservadoras y muy orgullosas. Expansión. Recuperado el 28 de abril de 2018 en https:/expansion.mx/especiales/2015/01/14/com o-saber-si-tu-estrategia-de-negocio-es-correcta

Niles, J. D. (2010). Homo narrans: the poetics and anthropology of oral literature. University of Pennsylvania Press.

Reputation Institute. (2018). Página principal de Reputation Institute. Recuperado el 28 de abril de 2018 en https: //www.reputationinstitute.com/

Rodríguez, A. (2015). Gestión de la reputación online. España: Ediciones CEF.

Sadows, J. \& Roche, L. (2013). Las siete reglas del storytelling: inspire a su equipo con liderazgo auténtico. Argentina: Granica.

Salmon, C. (2016). Storytelling: la máquina de fabricar historias y formatear las mentes. España: Península.

Sartre, J-P. (1938). La náusea. México: Editorial Época, $9^{a}$ edición.

Servitje, R. (2003). Bimbo. Estrategia de éxito empresarial. México: Pearson educación.

Servitje, R. (2009). Bimbo. Estrategia de éxito empresarial. México: Pearson educación, $2^{\mathrm{a}}$ edición.

Sinclair, J. (2005). The impact of stories. The Electronic Journal of Knowledge Management, 3 (1), 53-64.

Villeda, K. (2018). Secretos de negocios: así fue como nació el Osito Bimbo. Revista Alto Nivel. Recuperado el 30 de julio de 2018 en https://www.altonivel.com.mx/empresa s/negocios/asi-fue-como-nacio-osito-bimbo/ 